PyLe, A. J. H. (1954). J. gen. Microbiol. 11, 191-194

\title{
Some Aspects of the Amino Acid Metabolism of Penicillium chrysogenum
}

\author{
By A. J. H. PYLE \\ Research Department, Bacteriology Division, Boots Pure \\ Drug Co. Ltd., Nottingham
}

SUMMARY: Paper chromatographic methods were used to determine the amino acids in unhydrolysed corn steep liquor and to study the uptake and synthesis of amino acids by Penicillium chrysogenum. Of the eleven amino acids found in corn steep liquor all were taken up by the organism prior to the main period of penicillin formation. Only traces of ninhydrin-reacting material were present in the later samples of medium.

Glutamine, in addition to the eleven amino acids detected in corn steep liquors, was found in mycelium grown on medium containing corn steep liquor. Mycelium from Penicillium chrysogenum grown on medium containing inorganic nitrogen as sole nitrogen source showed the presence of the same twelve amino acids.

The gross nitrogen metabolism of various strains of Penicillium spp. used in the production of penicillin has been described previously by Koffler, Emerson, Perlman \& Burris (1945) and by Stefaniak, Gailey, Jarvis \& Johnson (1946), but less information is available on the detailed amino acid utilization by the organism in deep culture penicillin fermentations. This paper describes experiments carried out to determine the free amino acids present in corn steep liquor, to confirm their presence in sterilized corn steep liquor medium and to study their individual uptake by $\boldsymbol{P}$. chrysogenum during submerged culture. The synthesis of amino acids from chemically defined medium under similar conditions was also studied.

\section{METHODS}

Fermentation conditions. Experiments involving the uptake of amino acids were carried out in lactose + corn steep liquor medium (Rolinson \& Lumb, 1953) in 3 l. laboratory scale fermenters of the type described by Lumb \& Fawcett (1951). Chemically defined medium in which ammonium nitrogen replaced that of the corn steep liquor on an equivalent total nitrogen basis was used to determine the free amino acids synthesized by the organism under submerged culture conditions in shaken flasks (Lumb \& Fawcett, 1951). All fermentations were carried out in duplicate at $26^{\circ}$ with a non-pigment forming strain derived from Penicillium chrysogenum Q-176.

Preparation of samples for chromatography. The mycelium was filtered off under suction on a kieselguhr pad and the clarified culture filtrate was retained for chromatographic analysis. The mycelium was washed 3 times with sodium chloride solution $(0.9 \%, \mathrm{w} / \mathrm{v})$ to remove traces of medium and was then freeze-dried. This dried mycelium was ground in a mortar to break the cell walls and $0.2 \mathrm{~g}$. was extracted with $5 \mathrm{ml}$. ethanol $(80 \%, \mathrm{v} / \mathrm{v}$, in water) at room 
temperature for $48 \mathrm{hr}$., and then filtered. Corn steep liquor was diluted with 3 times its volume of water to facilitate application to the paper for chromatography. The various clarified medium samples were de-salted by electrodialysis before chromatography.

Chromatographic technique. The separation of the individual amino acids was carried out by ascending two-dimensional paper chromatography using Whatman no. 4 paper $(28 \times 28 \mathrm{~cm}$.) and phenol/water/formic acid mixture (Smith \& Agiza, 1951) in $\mathbf{N H}_{3}+\mathbf{H C N}$ atmosphere and acetone/aqueous urea mixture (Bentley \& Whitehead, 1950) as first and second solvent systems respectively. Equal volumes of similar samples were applied to separate papers with an Agla micrometer syringe so that the different chromatograms would be comparative. After development with the first solvent the chromatograms were dried overnight at room temperature and after the second solvent mixture for $2 \mathrm{hr}$. at room temperature. The spots were then detected by spraying with $0.1 \%(\mathrm{w} / \mathrm{v})$ ninhydrin in butanol and heating in an oven at $90^{\circ}$ for $15 \mathrm{~min}$. The unknown spots were compared with those from single known amino acids chromatographed under the same conditions. Chemical spot tests (Block \& Bolling, 1951; Bolling, Sober \& Block, 1949) supplemented this method of identification in the case of tryptophan, arginine and histidine.

\section{RESULTS}

From unhydrolysed corn steep liquor eleven ninhydrin-positive spots were detected which corresponded to aspartic acid, glutamic acid, glycine and/or serine, alanine, ornithine and/or lysine, tryptophan, proline, valine, leucine, arginine and histidine. Table 1 indicates semi-quantitatively the amounts of each. Many batches of corn steep liquor from different sources showed essentially the same composition. Leucine, isoleucine, valine and glutamic acid had previously been identified in unhydrolysed corn steep liquor by microbiological assay by Cardinal \& Hedrick (1948).

Uninoculated medium after sterilization, culture filtrates and mycelium were then examined for amino acids at the beginning of the fermentation and and at $24 \mathrm{hr}$. intervals (Table 1 ). All the amino acids originally detected in corn steep liquor were found in the medium after sterilization and at the beginning of the fermentation. All of them were taken up by the organism during fermentation and only traces were present in the $48 \mathrm{hr}$. and later samples of culture fluid. This contrasts with the situation found with some bacteria where amino acid uptake is strongly selective (Proom \& Woiwod, 1949). Traces of two new ninhydrin-positive substances were found in the medium during the course of the fermentation; one was identified as glutamine. The other spot, as yet unidentified, had $R_{F}$ values of 0.90 and 0.33 in the first and second solvent systems respectively, and thus lay near arginine.

The amino acid content of mycelium grown on corn steep liquor medium was next investigated. All the eleven amino acids found in corn steep liquor were found in the mycelium at some stage of the fermentation, and in general their concentration was at a maximum at $48 \mathrm{hr}$. and decreased slowly during 
the remainder of the fermentation. Glutamine was also detected in mycelium of $48 \mathrm{hr}$. and older but no other ninhydrin-positive material was found (Table 1). Thus the striking fall in the amino acid concentration in the culture fluid at $48 \mathrm{hr}$. corresponds to an accumulation within the mycelium; it is after this that the main phase of penicillin production takes place, lending support to previous findings by Wolf (1948), and by Narasimha Rao \& Venkataraman (1952) that these accumulated amino acids within the mycelium are intimately concerned with the formation of penicillin.

Table 1. Amino acids in corn steep liquor and in medium and mycelium during fermentation in lactose-corn steep liquor medium

\begin{tabular}{|c|c|c|c|c|c|c|c|c|c|c|c|c|}
\hline \multirow{2}{*}{$\begin{array}{l}\text { Amino } \\
\text { acid }\end{array}$} & \multirow{2}{*}{$\begin{array}{l}\text { Corn } \\
\text { steep } \\
\text { liquor }\end{array}$} & \multicolumn{6}{|c|}{$\begin{array}{l}\text { Culture fluid } \\
\text { Time of sampling (hr.) }\end{array}$} & \multicolumn{5}{|c|}{$\begin{array}{c}\text { Mycelium } \\
\text { Time of sampling (hr.) }\end{array}$} \\
\hline & & $\mathbf{0}$ & $\mathbf{2 4}$ & 48 & 72 & 96 & 120 & 24 & 48 & 72 & 96 & 120 \\
\hline Aspartic acid & ++ & ++ & ++ & $\mathbf{0}$ & + & + & $\mathbf{0}$ & + & ++ & ++ & + & + \\
\hline Glutamic acid & $+t$ & $+t$ & ++ & $\mathbf{0}$ & $\mathbf{0}$ & $\mathbf{0}$ & $\mathbf{0}$ & ++ & ++ & ++ & ++ & + \\
\hline $\begin{array}{l}\text { Glycine and/or } \\
\text { serine }\end{array}$ & $+t+$ & $+t+$ & +++ & + & + & + & + & $+t+$ & +++ & +++ & ++ & $+t$ \\
\hline Alanine & $+t+$ & $++t$ & +++ & $\mathbf{0}$ & + & + & + & $+t+$ & $++t$ & +++ & $++t$ & ++ \\
\hline Glutamine & o & 0 & $\mathbf{0}$ & $\mathbf{0}$ & $\mathbf{0}$ & 0 & + & 0 & + & ++ & $+t$ & $+t$ \\
\hline $\begin{array}{l}\text { Ornithine and/ } \\
\text { or lysine }\end{array}$ & ++ & ++ & ++ & 0 & 0 & 0 & 0 & $\mathbf{0}$ & + & $\mathbf{0}$ & $\mathbf{0}$ & $\mathbf{0}$ \\
\hline Tryptophan & ++ & ++ & ++ & $\mathbf{0}$ & 0 & 0 & $\mathbf{0}$ & $\mathbf{0}$ & $\mathbf{0}$ & ++ & ++ & $\mathbf{0}$ \\
\hline Proline & ++ & ++ & 0 & 0 & 0 & 0 & $\mathbf{0}$ & 0 & + & 0 & 0 & 0 \\
\hline Valine & $+t$ & $+t+$ & +++ & 0 & 0 & 0 & o & ++ & + & + & + & $\mathbf{0}$ \\
\hline Leucine & $+t+$ & $+t+$ & +++ & + & + & + & + & ++ & ++ & + & + & + \\
\hline Arginine & + & + & + & 0 & 0 & 0 & 0 & 0 & + & 0 & $\mathbf{0}$ & $\mathbf{0}$ \\
\hline Histidine & + & + & + & $\mathbf{0}$ & 0 & 0 & o & $\mathbf{0}$ & + & 0 & $\mathbf{0}$ & $\mathbf{0}$ \\
\hline Unidentified spot & $\mathbf{0}$ & $\mathbf{0}$ & + & + & + & + & + & 0 & 0 & 0 & $\mathbf{0}$ & 0 \\
\hline
\end{tabular}

+++ , large well-defined spot; ++ , small well-defined spot; + , trace; 0 , not detected.

Table 2 shows the results of similar experiments on fermentations in chemically defined medium where ammonium and nitrate were the sole sources of nitrogen. Chromatography of extracts from mycelium grown for 12 days showed the presence of the same twelve amino acids previously found in mycelium grown on corn steep liquor + lactose medium. As in the latter the glutamine, ornithine and/orlysine, tryptophan, arginine and histidine concentrations were very low, and the amino acid pattern is very similar. Thus the fungus readily synthesized its complement of amino acids from inorganic nitrogen. The medium at the end of the fermentation showed the presence of three spots corresponding to alanine, glycine and/or serine and leucine. Thus some excretion or autolysis of the mycelium had taken place.

The mycelium from corn steep liquor and from chemically defined medium was autolysed at $\mathrm{pH} 5.3$ for $\mathbf{7 2} \mathrm{hr}$. at $36^{\circ}$ under a layer of toluene and the autolysates examined as before. (Table 2). The only changes detected were the disappearance of glutamine and some loss of tryptophan.

An interesting feature of all these analyses is in the similarity of the free amino acids in the corn steep liquor and those liberated from the mycelium after hydrolysis. 
Table 2. A comparison of the amino acids found in fresh and autolysed mycelium grown in corn steep liquor medium and chemically defined medium

\begin{tabular}{|c|c|c|c|c|c|}
\hline \multirow[b]{2}{*}{ Amino Acid } & \multicolumn{2}{|c|}{$\begin{array}{l}\text { Mycelium grown } \\
\text { on medium } \\
\text { containing } \\
\text { corn steep } \\
\text { liquor }\end{array}$} & \multicolumn{2}{|c|}{$\begin{array}{l}\text { Mycelium grown } \\
\text { on medium } \\
\text { containing } \\
\text { inorganic } \\
\text { nitrogen }\end{array}$} & \multirow{2}{*}{$\begin{array}{c}\text { Amino } \\
\text { acids in } \\
\text { chemically- } \\
\text { defined } \\
\text { medium } \\
\text { after } \\
\text { fermentation }\end{array}$} \\
\hline & Fresh & Autolysed & Fresh & Autolysed & \\
\hline Aspartic acid & $+t$ & ++ & ++ & ++ & $\mathbf{0}$ \\
\hline Glutamic acid & ++ & +++ & ++ & $+t$ & 0 \\
\hline $\begin{array}{l}\text { Glycine and/ } \\
\text { or serine }\end{array}$ & $++t$ & +++ & +++ & $++t$ & + \\
\hline Alanine & $++t$ & +++ & $++t$ & +++ & ++ \\
\hline Glutamine & + & 0 & + & o & 0 \\
\hline $\begin{array}{l}\text { Ornithine and/ } \\
\text { or lysine }\end{array}$ & + & ++ & + & ++ & 0 \\
\hline Tryptophan & ++ & + & + & $\mathbf{0}$ & $\mathbf{0}$ \\
\hline Proline & + & ++ & ++ & $+t$ & $\mathbf{0}$ \\
\hline Valine & + & +++ & $++t$ & +++ & 0 \\
\hline Leucine & ++ & +++ & $+t+$ & +++ & ++ \\
\hline Arginine & + & ++ & + & + & 0 \\
\hline Histidine & + & ++ & + & + & 0 \\
\hline
\end{tabular}

+++ , large well-defined spot; ++ , small well-defined spot; + , trace; 0 , not detected.

I am indebted to Mr C. E. Coulthard and Dr M. Lumb for their interest in the work, and to Mr R. Fawcett and Mr J. Ransom for technical assistance.

\section{REFERENCES}

Bentley, H. R. \& Whitehead, J. K. (1950). Water-miscible solvents in the separation of amino-acids by paper chromatography. Biochem. J. 46, 341.

Block, R. J. \& Bolling, D. (1951). The Amino Acid Composition of Proteins and Foods. Springfield, Ill.: C. C. Thomas.

Bolling, D., Sober, H. A. \& Block, R. J. (1949). Quantitative separation and determination of small amounts of histidine and tyrosine employing paper chromatography. Fed. Proc. 8, 185.

Cardinal, E. V. \& Hedrick, L. R. (1948). Microbiological assay of corn steep liquor for amino acid content. J. biol. Chem. 172, 609.

Koffler, H., Emerson, R. L., Perlman, D. \& Burris, R. H. (1945). Chemical changes in submerged penicillin fermentations. J. Bact. 50, 517.

Lumb, M. \& FAwCETT, R. (1951). Improvements in experimental fermenters. $J$. appl. Chem. 1, S 94.

Narasimha Rao, P. L. \& Venkataraman, R. (1952). Nitrogen metabolism of Penicillium chrysogenum Q-176. Experientia, 8, 350.

Proom, H. \& Worwod, A. J. (1949). The examination, by partition paper chromatography, of the nitrogen metabolism of bacteria. J. gen. Microbiol. 3, 319 .

Rolinson, G. N. \& Lumb, M. (1953). The oxidation of lard oil by Penicillium chrysogenum. J. gen. Microbiol. 9, 385.

Smith, A. M. \& AGIZA, A. H. (1951). The amino acids of several grassland species, cereals and bracken. J. Sci. Fd Agric. 2, 503.

Stefaniak, J. J., Gailey, F. B., Jarvis, F. G. \& Johnson, M. J. (1946). The effect of environmental conditions on penicillin fermentations with Penicillium chrysogenum X-1612. J. Bact. 52, 119.

Wolf, F. T. (1948). The amino acid metabolism of Penicillium chrysogenum Q-176. Arch. Biochem. 16, 143.

(Received 31 March 1954) 